\title{
Intensive Poultry Farming Practices Influence Antibiotic Resistance Profiles in Pseudomonas aeruginosa Inhabiting Nearby Soils
}

\author{
Shaheena Kousar' \\ Nikhar Rehman' \\ Asghar Javed (iD ${ }^{2}$ \\ Aamir Hussain ${ }^{3}$ \\ Muhammad Naeem ' \\ Samra Masood' \\ Hafiz Arslan Ali ${ }^{1}$ \\ Amna Manzoor \\ Aleem Ahmed Khan' \\ Ahmed Akrem ' \\ Fatima lqbal ${ }^{4}$ \\ Aqsa Zulfiqar' \\ Muhammad Bilal Jamshaid' \\ Muhammad Waqas' \\ Asma Waseem' \\ Muhammad Qamar Saeed (iD) \\ 'Dr. Ghulam Nabi Chaudhry Laboratory \\ of Microbial Technologies, Department of \\ Microbiology and Molecular Genetics, \\ Institute of Pure and Applied Biology, \\ Bahauddin Zakariya University, Multan, \\ Pakistan; '2Pathology Department, \\ Nishtar Medical University, Multan, \\ Pakistan; ${ }^{3}$ Institute of Basic Medical \\ Sciences, Khyber Medical University, \\ Peshawar, Pakistan; ${ }^{4}$ MINAR, Multan \\ Institute of Nuclear Medicine and \\ Radiotherapy, Nishter Medical University, \\ Multan, Pakistan
}

Correspondence: Muhammad Qamar Saeed

Dr. Ghulam Nabi Chaudhry Laboratory of Microbial Technologies, Department of

Microbiology, Institute of Pure and

Applied Biology, Bahauddin Zakariya

University, Multan, Pakistan

Tel +92-333-023I222

Email mqamarsaeed@bzu.edu.pk
Background: The drastic increase in use of antibiotics as a mandatory part of production in poultry and livestock has led to the development of bacterial resistance against antibiotics. The spread of resistant bacteria from poultry to humans increases the risk of treatment failure by antibiotics because of resistance genes transfer.

Study Objective: The objective of the study was to estimate and compare the $P$. aeruginosa resistance profile collected from areas around the poultry farm premises and areas at least 500 meters away from the nearest poultry farm. We studied the effect of antibiotic usage in farms on the bacterial profile present in the upper layer of soil.

Methodology: A total of 1,200 moist soil samples were collected from areas within a 25 meters range of poultry farms and areas that had no poultry farms in its 500 meters vicinity. $P$. aeruginosa was cultured and isolated. The antibiotic susceptibility profile was carried out by Kirby-Bauer disc diffusion method and results were analyzed according to CLSI guidelines. Statistical analysis was carried out to check the significance of results.

Results: A total of 300 P. aeruginosa isolates were isolated, among which 140 isolates were isolated from areas around the poultry farm premises and had higher prevalence of antibiotic resistance. A total of 160 isolates were isolated from areas outside the poultry farm range. Resistance was not as high as in the isolates from around the farm. The ESBL production was higher in the isolates that were in close contact with the poultry farm as compared to the isolates away from the farm.

Conclusion: Use of antibiotics in the poultry farm for production significantly increases the resistance in bacterial strains present in the upper layer of soil around the poultry farm within at least a 25 meter range.

Keywords: antibiotic resistance, $P$. aeruginosa, poultry, MDR

\section{Introduction}

Antibiotics have been used in human medicine and livestock welfare. However, misuse of antimicrobials in any field result in the development of antibiotic resistant pathogenic microbes that affect both human and animal health. ${ }^{1}$ From the last few decades, use of antimicrobials in poultry production has been increased tremendously. Apart from using for therapeutic purposes, antibiotics are being used as growth promoters and prophylaxis. ${ }^{2,3}$ Excessive use of antibiotics for poultry production is the leading cause of resistance development in bacteria. Many pathogenic bacteria reside in the intestinal tract of animals that are transmitted to the humans via fecal material or the food chain, becoming a source of public health 
problems. ${ }^{2,4}$ Many studies provide evidence of spreading resistant bacterial strains from food animals to humans in the USA, European countries, and Denmark. ${ }^{5,6}$ Commonly known MDR pathogens are E. coli, A. baumannii, Klebsiella, Salmonella. and P. aeruginosa. Transmission of $P$. aeruginosa resistant to amoxicillin, augmentin, tetracycline, cotrimoxazole, and chloramphenicol from poultry environment to humans was reported in Nigeria. ${ }^{7}$

Disposal of animal wastes as a manure is another source of transmission of resistant pathogens from animal farms to the soil. This problem has been increased due to the concentrated animal feeding practices. As a result, resistant bacteria and antimicrobials residues accumulate in the soil and proliferate antibiotic resistance in soil inhabiting bacteria. ${ }^{8}$

Pseudomonas is a gram-negative, oxidase positive, aerobic bacterium. It is ubiquitous in aqueous environment and soil. It is a leading cause of pseudomoniasis, respiratory infections, sinusitis, septicemia, and endocarditis in poultry birds like chickens, geese, and turkeys. ${ }^{9}$ Studies provide evidence of transmission of pseudomonas infections from broiler chicks to humans directly. ${ }^{10}$ In Pakistan, $28 \%$ of cases of necropsy in chickens are due to Pseudomonas aeruginosa. Further investigation reveals that these bacterial strains were resistant to erythromycin, ceftriaxone, ciprofloxacin, and colistin. ${ }^{9}$

Nowadays, poultry is a flourishing industry in Pakistan. People are rearing chickens in control sheds and semicontrol sheds in which thousands of chickens are kept at a time and a large amount of antibiotics are used to increase their growth rate. As a result of selection pressure, bacteria are becoming resistant to commonly used antibiotics. Exhaust fans are used to maintain the temperature of the control-sheds. These fans expel out the bacteria and antibiotic residues from the poultry farms into the surroundings. Contamination of the soil with poultry litter may induce resistance in soil inhabiting bacteria. ${ }^{11}$ The purpose of our study is to determine the pattern of resistance in $P$. aeruginosa at different distances from poultry farms.

\section{Methodology}

\section{Sampling}

We selected 20 poultry farms and 20 areas which did not have any poultry farm within a 500-meter range. Both these areas represented the same geographical regions. In total, 600 samples were collected from each of the two types of area (1,200 total). We collected around 30 samples from around each poultry farm and 30 samples from each area having no poultry farm. The samples were collected from the upper layer of soil and were stored in sterile tubes.

\section{Isolation and Identification of $P$. aeruginosa}

One gram of each soil sample was added in separate vials containing sterile saline solution. The samples were directed to 10 -fold serial dilution before inoculation. The samples were then inoculated in nutrient broth and were incubated overnight followed by streaking on MacConkey agar. The streaked plates were incubated overnight at $37^{\circ} \mathrm{C}$. The colonies that were oxidase positive were further streaked on Cetrimide agar for isolation of $P$. aeruginosa. Bacterial colonies were confirmed by biochemical tests. $^{12}$

\section{Antimicrobial Susceptibility Testing}

Kirby-Bauer disc diffusion method was used to check the susceptibility of isolated bacteria against antibiotics. The inhibition zones obtained from each bacterium after incubation with the antibiotic disc were compared following CLSI standards. In total, 14 antibiotics were selected against which the susceptibility of bacteria was checked.

\section{ESBL Detection}

ESBL in $P$. aeruginosa were detected by disc diffusion method. The antibiotics used were cefepime, ceftazidime, cefotaxime, and cefpodoxime. The diameter of zone of inhibition was noted on Excel sheets. Data was copied on a Mast group ESBL and CARBA plus calculator spreadsheet. The results were either positive or negative for ESBL production in $P$. aeruginosa.

\section{Statistical Analysis}

MS Excel was used to carry out the statistical analysis of the collected data. Percentages and mean values were calculated. Chi-square test was carried as mentioned in another study. ${ }^{13}$ Briefly, we hypothesized that antibiograms of the samples collected from regions with no poultry farms within a 500 meter range represent normal baseline resistance values. Hence similar resistance values were "expected" from samples obtained from around poultry farms, if farms had no influence on their immediate environment. $P$-value was calculated and $P<0.05$ was referred to as statistically significant, indicating a correlation between poultry farm proximity and the emergence of resistance. 


\section{Results}

A total of 1,200 soil samples were collected from two types of areas, areas within a 25 -meter range of poultry farms and others that had no farm in at least a 500-meter area. Six hundred samples were collected from each type of area for the isolation of $P$. aeruginosa.

\section{Bacterial Profile and Antibiotics Resistance}

From the 1,200 samples, 300 isolates of $P$. aeruginosa were isolated; $140(46.6 \%)$ isolates were isolated from areas near poultry farms and $160(53.3 \%)$ were isolated from areas that had no poultry farm in a 500-meter vicinity (Table 1). Among the 140 isolates of $P$. aeruginosa isolated from an area around a poultry farm, 105 (75\%), 109 (77\%), 117 (83.5\%), 96 (68.5\%), 75 (53.5\%), 114 $(81.4 \%), 125(89.2 \%)$, and $112(80 \%)$ were sensitive, and 35 (25\%), 31 (22.1\%), 23 (16.4\%), 44 (31.4\%), 65 (46.4\%), $26(18.5 \%), 15(10.7 \%)$, and $28(20 \%)$ were resistant to piperacillin-tazobactam, colistin, meropenem, ticarcillin-clavulanate, cefepime, polymyxin, gentamicin, and ciprofloxacin, respectively. Among 160 isolates of P. aeruginosa, 140 (87.5\%), 146 (91.2\%), 149 (93.1\%), $124(77.5 \%), 122$ (76.2\%), $151(94.3 \%), 152(95 \%)$, and 145 (90.6\%) were resistant and 20 (12.5\%), $14(8.7 \%), 11$

Table I Resistance Pattern of $P$. aeruginosa Isolates Isolated from Around the Farm and Outside the Farm

\begin{tabular}{|l|c|c|}
\hline Antibiotics & $\begin{array}{l}\text { P. aeruginosa from } \\
\text { Around the Farm } \\
(\mathbf{n = 1 4 0 )}\end{array}$ & $\begin{array}{l}\text { P. aeruginosa from } \\
\text { Outside the Farm } \\
(\mathbf{n}=160)\end{array}$ \\
\hline CST & $44(31.4 \%)$ & $36(22.5 \%)$ \\
OFX & $47(33.5 \%)$ & $27(16.8 \%)$ \\
PMB & $65(46.4 \%)$ & $38(23.7 \%)$ \\
TIC & $31(22.1 \%)$ & $14(8.7 \%)$ \\
TZP & $35(25 \%)$ & $20(12.5 \%)$ \\
AMK & $16(11.4 \%)$ & $7(4.3 \%)$ \\
LVX & $51(36.4 \%)$ & $32(20 \%)$ \\
CIP & $26(18.5 \%)$ & $9(5.6 \%)$ \\
FEP & $28(20 \%)$ & $15(9.4 \%)$ \\
MEM & $15(10.7 \%)$ & $8(5 \%)$ \\
GEN & $23(16.4 \%)$ & $11(6.8 \%)$ \\
ATM & $88(62.8 \%)$ & $45(28.1 \%)$ \\
TOB & $4(2.8 \%)$ & $1(0.6 \%)$ \\
IPM & $49(35 \%)$ & $33(20.6 \%)$ \\
\hline
\end{tabular}

Abbreviations: CST, colistin; OFX, ofloxacin; PMB, polymyxin; TIC, ticarcillinclavulanate; TZP, piperacillin-tazobactam; AMK, amikacin; LVX, levofloxacin; CIP, ciprofloxacin; FEP, cefepime; MEM, meropenem; GEN, gentamicin; ATM, aztreonam; TOB, tobramycin; IPM, imipenem.
(6.8\%), $36(22.5 \%), 38(23.7 \%), 9(5.6 \%), 8(5 \%)$, and 15 $(9.3 \%)$ were resistant to piperacillin-tazobactam, colistin, meropenem, ticarcillin-clavulanate, cefepime, polymyxin, gentamicin and ciprofloxacin, respectively. The overall resistance pattern was higher in the isolates isolated from area within the premises of a poultry farm.

\section{Antibiotics Sensitivity Profile of P. aeruginosa}

The antibiotics sensitivity was checked with Kirby-Bauer disc diffusion method. The data of this profile suggests that the number of sensitive isolates is higher in the isolates from farm-free areas as compared to the isolates isolated from areas around a poultry farm (Table 2).

\section{Multidrug Resistant $P$. aeruginosa}

Multidrug resistance prevailed in the isolates that were isolated from the vicinity of a poultry farm. A total of $105(75 \%)$ isolates out of 140 were found to be MDR and among 160 Pseudomonas aeruginosa isolated from the area that had no poultry farm nearby, $85(53.1 \%)$ were MDR. These results indicate the role of the poultry farm in spreading multidrug resistance in their immediate surroundings (Table 3).

\section{ESBL Production in $P$. aeruginosa}

Among 140 isolates of $P$. aeruginosa isolated from the poultry farm area, 24 (17.1\%) were ESBL producers, while among 160 isolates isolated from areas that had no poultry farms in a 500-meter vicinity, only $7(4.3 \%)$ were ESBL producers. In this case, the ESBL producing proportion is higher in the $P$. aeruginosa isolates that were isolated from the premises of a controlled shed (Table 3).

\section{Discussion}

Generally, when antibiotics are given on a poultry farm, they tend to kill the sensitive isolates and only the isolates that possess special traits of resistance to antibiotics are left behind. These kind of bacteria then transmit their traits and genes to other bacteria via plasmids or horizontal gene transfer. ${ }^{14}$ It has been shown that poultry farms harbor resistant bugs, and the more intensive the farming practice, the higher is the resistance level. ${ }^{15}$ Although environmental drivers of resistance as well as transfer of resistance in food chain is well documented; there is a scarcity of peerreviewed studies aimed at understanding the effects of intensive poultry farming in the spread of resistance. ${ }^{4,16}$ 
Table 2 Comparison of Sensitivity and Resistance Profile, Chi-Square, and $P$-value of $P$. aeruginosa

\begin{tabular}{|c|c|c|c|c|c|c|c|}
\hline \multicolumn{4}{|c|}{ Number of Sensitive and Resistant Isolates } & \multicolumn{4}{|c|}{$\begin{array}{l}\text { For Chi-Square Value, No. of } P . \text { aeruginosa Isolates Have } \\
\text { Been Normalized to } 160\end{array}$} \\
\hline Antibiotics & Pattern & $\begin{array}{l}\text { P. aeruginosa } \\
\text { Within } 25 \\
\text { Meters }\end{array}$ & $\begin{array}{l}\text { P. aeruginosa from } \\
\text { Outside the Farm }\end{array}$ & $\begin{array}{l}\text { P. aeruginosa } \\
\text { Within } 25 \\
\text { Meters }\end{array}$ & $\begin{array}{l}\text { P. aeruginosa from } \\
\text { Outside the Farm }\end{array}$ & $\begin{array}{l}\text { Chi- } \\
\text { Square }\end{array}$ & $P$-value \\
\hline TZP & $\begin{array}{l}S \\
R\end{array}$ & $\begin{array}{l}105 \\
35\end{array}$ & $\begin{array}{l}140 \\
20\end{array}$ & $\begin{array}{l}120 \\
40\end{array}$ & $\begin{array}{l}140 \\
20\end{array}$ & 22.9 & $<0.001$ \\
\hline CST & $\begin{array}{l}S \\
R\end{array}$ & $\begin{array}{l}96 \\
44\end{array}$ & $\begin{array}{l}124 \\
36\end{array}$ & $\begin{array}{l}110 \\
50\end{array}$ & $\begin{array}{l}124 \\
36\end{array}$ & 7 & 0.005 \\
\hline MEM & $\begin{array}{l}S \\
R\end{array}$ & $\begin{array}{l}125 \\
15\end{array}$ & $\begin{array}{l}152 \\
8\end{array}$ & $\begin{array}{l}143 \\
17\end{array}$ & $\begin{array}{l}152 \\
8\end{array}$ & 10.7 & 0.001 \\
\hline TIC & $\begin{array}{l}S \\
R\end{array}$ & $\begin{array}{l}109 \\
31\end{array}$ & $\begin{array}{l}146 \\
14\end{array}$ & $\begin{array}{l}125 \\
35\end{array}$ & $\begin{array}{l}146 \\
14\end{array}$ & 34.5 & $<0.001$ \\
\hline FEP & $\begin{array}{l}S \\
R\end{array}$ & $\begin{array}{l}112 \\
28\end{array}$ & $\begin{array}{l}145 \\
15\end{array}$ & $\begin{array}{l}128 \\
32\end{array}$ & $\begin{array}{l}145 \\
15\end{array}$ & 21.3 & $<0.001$ \\
\hline PMB & $\begin{array}{l}S \\
R\end{array}$ & $\begin{array}{l}75 \\
65\end{array}$ & $\begin{array}{l}122 \\
38\end{array}$ & $\begin{array}{l}86 \\
74\end{array}$ & $\begin{array}{l}122 \\
38\end{array}$ & 44.7 & $<0.001$ \\
\hline GEN & $\begin{array}{l}S \\
R\end{array}$ & $\begin{array}{l}117 \\
23\end{array}$ & $\begin{array}{l}149 \\
11\end{array}$ & $\begin{array}{l}134 \\
26\end{array}$ & $\begin{array}{l}149 \\
11\end{array}$ & 22 & $<0.001$ \\
\hline CIP & $\begin{array}{l}S \\
R\end{array}$ & $\begin{array}{l}114 \\
26\end{array}$ & $\begin{array}{l}151 \\
9\end{array}$ & $\begin{array}{l}130 \\
30\end{array}$ & $\begin{array}{l}151 \\
9\end{array}$ & 51.9 & $<0.001$ \\
\hline
\end{tabular}

In this backdrop, it was of interest to see whether the resistance developed inside farms is transferred to the outside environment.

The transfer of resistant bacteria from farm to environment can occur through untreated manure dispersal and exhaust fans. Once transferred, the resistant bacteria colonize in the gut of the human body and the genes responsible for resistance are transferred to the other gut bacteria, thus decreasing the efficiency of treatment. ${ }^{17} \mathrm{~A}$ serious public health hazard is under development as the proportion of resistant bacteria are increasing in the poultry due to excessive use of antibiotics in the farms. ${ }^{18}$
In this study we compared the antibiotic resistance profile of $P$. aeruginosa isolated from 20 areas that had poultry farms in their 25 meter range and from the same number of areas that did not have any farm within 500 meters. A total of 1,200 soil samples were collected and 300 isolates of $P$. aeruginosa were isolated. According to the obtained results, the isolated $P$. aeruginosa isolates from area within the range of poultry farm had increased rate of resistance as compared to the isolates from the area far away from poultry farm. This indicates that the antibiotics being used in the farm are increasing the resistance in bacteria. In general, the significant resistance was

Table 3 Odds Ratio and $P$-value of ESBL Production and MDR Isolates of $P$. aeruginosa

\begin{tabular}{|c|c|c|c|c|c|c|}
\hline \multirow[t]{2}{*}{ Variables } & \multicolumn{2}{|c|}{ ESBL Production } & \multirow[t]{2}{*}{ Odds Ratio } & \multicolumn{2}{|c|}{ Multidrug Resistance } & \multirow[t]{2}{*}{ Odds Ratio } \\
\hline & Yes & No & & Yes & No & \\
\hline P. aeruginosa within 25 meters & 24 & 116 & $4.5(1.8-10.8)$ & 112 & 28 & I3.7 (7.9-24.0) \\
\hline P. aeruginosa from outside the farm & 7 & 153 & $P \leq 0.0007$ & 36 & 124 & $P \leq 0.0001$ \\
\hline
\end{tabular}

Abbreviations: ESBL, extended spectrum $\beta$-lactamases; MDR, multidrug resistance. 
observed in the isolates against antibiotics which were being heavily used inside the farm. It can be concluded that the pattern of resistance in the surrounding area of a poultry farm is highly influenced by the choice of antibiotics used inside the farm.

It is believed that the birds' fecal material can serve a potential source of contamination of water and soil nearby, thus infecting the humans consuming this water particularly in rural areas. The contamination of soil can lead to deposition of resistant bacteria in domestically grown fruits and vegetables ultimately entering the human gut, developing resistance, and being a barrier in treatment of infections with antibiotics. ${ }^{19}$

Significantly higher numbers of ESBL and MDR isolates were prevalent in areas within the poultry farm premises. It is obvious that excessive use of antibiotics in poultry to increase the growth of broiler chicken is developing a serious sort of resistance in bacteria by production of ESBL. The isolates are also becoming MDR because they are showing resistance to at least three classes of antibiotics. The results indicated a significant difference in resistance profile and ESBL production in $P$. aeruginosa isolates isolated from areas within the poultry farm and areas far from the farm.

The preventive measures that can be adopted to minimize the spread of MDR $P$. aeruginosa from poultry to humans are the proper handling of raw products, fecal material of birds, proper disposal of waste, and adequate cooking of meat in order to sterilize it. ${ }^{20}$

\section{Conclusion}

This study underlines the fact that use of antibiotics in poultry, although increasing the growth of chickens, is also posing serious health issues due to the transfer of resistance from within the poultry farms to the outside. This can ultimately transpire into a public health problem. These initial findings also emphasize the importance of thorough ecological investigations to fully understand the role of poultry farming in transferring resistance through the food chain. Additionally, alternate ways, more akin to economic realities of the third world, to increase growth and limit infections in poultry farms need to be explored.

\section{Acknowledgments}

We acknowledge Bahauddin Zakariya University for their annual research grant.

\section{Funding}

Annual research grant of BZU.

\section{Disclosure}

The authors declare no conflicts of interest in this work.

\section{References}

1. Aarestrup FM. Monitoring of antimicrobial resistance among food animals: principles and limitations. $J$ Vet Med B. 2004;51(89):380-388. doi:10.1111/j.1439-0450.2004.00775.x

2. Aarestrup FM. Association between the consumption of antimicrobial agents in animal husbandry and the occurrence of resistant bacteria among food animals. Int J Antimicrob Agents. 1999;12(4):279-285. doi:10.1016/s0924-8579(99)90059-6

3. Murphy D, Ricci A, Auce Z, et al. EMA and EFSA joint scientific opinion on measures to reduce the need to use antimicrobial agents in animal husbandry in the European Union, and the resulting impacts on food safety (RONAFA). EFSA J. 2017;15:1. doi:10.2903/j. efsa.2017.4666

4. Manyi-Loh C, Mamphweli S, Meyer E, Okoh A. Antibiotic use in agriculture and its consequential resistance in environmental sources: potential public health implications. Molecules. 2018;23(4). doi: $10.3390 /$ molecules 23040795

5. Aarestrup FM. Veterinary drug usage and antimicrobial resistance in bacteria of animal origin. Basic Clin Pharmacol Toxicol. 2005;96 (4):271-281. doi:10.1111/j.1742-7843.2005.pto960401.x

6. Aarestrup FM, Bager F, Jensen NE, Madsen M, Meyling A, Wegener HC. Surveillance of antimicrobial resistance in bacteria isolated from food animals to antimicrobial growth promoters and related therapeutic agents in Denmark. APMIS Acta Pathol Microbiol Immunol Scand. 1998;106(1-6):606-622. doi:10.1111/j.16990463.1998.tb01391.x

7. Omoya FO, Ajayi KO. Antibiotic resistance pattern of pathogenic bacteria isolated from poultry droppings in Akure, Nigeria. Futa J Res Sci. 2016;12:219-227.

8. Ghosh S, LaPara TM. The effects of subtherapeutic antibiotic use in farm animals on the proliferation and persistence of antibiotic resistance among soil bacteria. ISME J. 2007;1(3):191-203. doi:10.1038/ ismej.2007.31

9. Kumar Y. Antimicrobial Resistance: A Global Threat. BoD - Books on Demand; 2019.

10. Badr JM, El Saidy FR, Abdelfattah AA. Emergence of multi-drug resistant Pseudomonas aeruginosa in Broiler Chicks. Int J Microbiol Biotechnol. 2020;5(2):41. doi:10.11648/j.ijmb.20200502.11

11. Yang Y, Ashworth AJ, Willett C, et al. Review of antibiotic resistance, ecology, dissemination, and mitigation in U.S. broiler poultry systems. Front Microbiol. 2019;10. doi:10.3389/fmicb.2019.02639

12. Sivasakthivelan P, Rani GU Mrs. Comparative study for biosurfactant production by using Bacillus subtilis and Pseudomonas aeruginosa. Bot Res Int. 2009;2(4):284-287.

13. Perla R, Carifio J. Use of the chi-square test to determine significance of cumulative antibiogram data. Am J Infect Dis. 2005;1. doi:10.3844/ajidsp.2005.162.167

14. Gould IM. The epidemiology of antibiotic resistance. Int $J$ Antimicrob Agents. 2008;32:S2-S9. doi:10.1016/j. ijantimicag.2008.06.016

15. Gohar M, Mustafa A, Aziz J, et al. Controlled-shed poultry farming practices in Pakistan select for antibiotic resistant Escherichia coli. $J \quad$ Glob Antimicrob Resist. 2018;12:24-25. doi:10.1016/j. jgar.2017.11.015

16. Verraes C, Van Boxstael S, Van Meervenne E, et al. Antimicrobial resistance in the food chain: a review. Int $J$ Environ Res Public Health. 2013;10(7):2643-2669. doi:10.3390/ijerph10072643 
17. Randall LP, Ridley AM, Cooles SW, et al. Prevalence of multiple antibiotic resistance in 443 Campylobacter spp. isolated from humans and animals. $J$ Antimicrob Chemother. 2003;52(3):507-510. doi: $10.1093 / \mathrm{jac} / \mathrm{dkg} 379$

18. Lukášová J, Šustáčková A. Enterococci and antibiotic resistance. Acta Vet Brno. 2003;72(2):315-323. doi:10.2754/avb200372020315
19. Apata DF. Antibiotic resistance in poultry. Int J Poult Sci. 2009;8 (4):404-408. doi:10.3923/ijps.2009.404.408

20. Catry B, Laevens H, Devriese LA, Opsomer G, de Kruif A. Antimicrobial resistance in livestock. $J$ Vet Pharmacol Ther. 2003;26(2):81-93. doi:10.1046/j.1365-2885.2003.00463.x

\section{Publish your work in this journal}

Infection and Drug Resistance is an international, peer-reviewed openaccess journal that focuses on the optimal treatment of infection (bacterial, fungal and viral) and the development and institution of preventive strategies to minimize the development and spread of resistance. The journal is specifically concerned with the epidemiology of antibiotic resistance and the mechanisms of resistance development and diffusion in both hospitals and the community. The manuscript management system is completely online and includes a very quick and fair peerreview system, which is all easy to use. Visit http://www.dovepress.com/ testimonials.php to read real quotes from published authors. 